\title{
Stabilisation of Dispersive Soil Using Fly Ash, Bottom Ash and Hydrated Lime
}

\author{
Sitharika A.V.D.T. ${ }^{1}$, Udamulla K.M.L.A. ${ }^{2 *}$ \\ ${ }^{1}$ Department of Civil Engineering, IESL College of Engineering, Sri Lanka \\ ${ }^{2}$ Department of Civil Engineering, The Open University, Sri Lanka \\ *lakshika0807@hotmail.com
}

\begin{abstract}
Dispersive soils are structurally unstable soil and it is highly flexible to erosion and piping. Using this type of soil for infrastructure programs like hydraulically structures, earth dams, road embankments and railways can lead to problems. Therefore, these dispersive soils need to be stabilized. Therefore, the research attempts to seek the feasibility of stabilization of dispersive soil using fly-ash, bottom-ash and hydrated lime. Fly ash and bottom ash are two of the waste materials generated from the thermal power plant located at Norrochcholai. At present, storage and disposal of these two by-products are a critical issue. In this research identifying dispersive soils using pinhole test and crumb test from the location of Kudaoya reservoir has been carried out. Each test was conducted using three replicates. The engineering properties of dispersive soil have been determined using Atterberg limit test, standard proctor compaction test and permeability test. The optimum mixture of fly ash, bottom ash and hydrated lime to remove the depressiveness of the soil was carried out using the pinhole test. Thereafter, the engineering properties (dry density, permeability) were also assessed for optimum stabilized mix proportions of stabilizing agents. The dispersive soils in Kuda Oya area was found to be moderately dispersive as per the pinhole test results. Two optimum proportion mixtures were identified as $2 \%$ of hydrated lime+ $98 \%$ of dispersive soil and $2 \%$ of bottom ash $+98 \%$ of dispersive soil to remove the dispersiveness effectively based on the results of pinhole test and cost analysis. When the dry densities of these two mixtures were compared it was found that $2 \%$ of hydrated lime+ $98 \%$ of dispersive soil were higher than that of $2 \%$ of bottom ash $+98 \%$ of dispersive soil. Therefore, $2 \%$ of hydrated lime $+98 \%$ of dispersive soil was selected as the optimum solution. The maximum dry density of this sample ( $2 \%$ of hydrated lime+ $98 \%$ of dispersive soil) was found to be $1.6 \mathrm{mg} / \mathrm{m}^{3}$ which was higher than the dry density $\left(1.54 \mathrm{mg} / \mathrm{m}^{3}\right)$ of virgin dispersive soil sample. The plasticity index of the stabilized dispersive soil mixture (31\%) was less than the virgin soil (35\%). However, the coefficient of permeability of the optimum selected mixture $2.56 \times 10^{-8} \mathrm{~cm} / \mathrm{s}$ was less than that that of the virgin soil $\left(1.41 \times 10^{-7} \mathrm{~cm} / \mathrm{s}\right)$. Therefore, based on these results, the selected optimum proportion ( $2 \%$ of hydrated lime with $98 \%$ of soil) can be used for stabilisation of dispersive soils.
\end{abstract}

Keywords: Dispersive soils, Erosion and piping, Stabilising agents, Engineering properties 